\title{
BREATHING FREQUENCY IN SLEEP RELATED RESPIRATORY DISTURBANCES
}

\author{
MÁRCIA PRADELLA:
}

SUMMARY - In normal adults, breathing frequency (f) is highly reproducible within an individual ranging from 8 to 25 min-1; during sleep, $f$ is known to change only minimally. This variable is rarely reported in studies of adults with various sleep related respiratory disturbances (SRRD). We occasionally observed a spectacular increase of $f$ during sleep in patients with SRRD associated with hypopnea and 02 desaturation. We undertook a retrospective study of 650 consecutive rall-night polysomnographic recordings, in order to evaluate how often such an increase in breathing frequency occurs and with which factors it is associated. We excluded patients with nujor respiratory failure. We found 16 patients (11 males; mean $\pm \mathrm{SD}$, age: $45 \pm 13 \mathrm{yrs}$; body mass index (BMI): $44 \pm 11 \mathrm{~kg} / \mathrm{m}(2)$ with $\mathrm{f}>25 \mathrm{~min}-1$ during sleep (tachypneic group, $T$ ). We performed a one-for-one matching for sex, age and BMI between the $T$ and a control (C) group (age: $45 \pm 12$ yrs; BMI $44 \pm 10 \mathrm{~kg} / \mathrm{m} 2$ ), with similar sleep disturbances but normal $f$ during sleep. We compared the $f$ in each vigilance state by averaging five measurements of $f$, each of one minute duration in a stable period. We observed that: $C$ patients showed no significant change in $f$ in any vigilance state; $T$ patients showed a higher $f$ already during wakefulness $(p<0.05)$ and $f$ increased significantly in all sleep stages $(<0.01)$. We compared the two groups for many clinical and polysomnographic variables. Significant statistical differences were observed for: $f$, arterial CO2 tension (PaCO2), vital capacity (VC), forced expiratory volume at one second (FEV1) and pulse frequency (PF).

KEY WORDS: breathing frequency, polysomnographic recording, sleef related respiratory disturbances.

Frequência respiratória observada en pacientes com problemas respiratórios associados ao sono.

RESUMO - Em adultos normais, a frequência respiratória (f) varia de 8 a 25 min-1 com grande reprodutividade intraindividual: durante o sono, $f$ é quase invariável. Esta variável tem sido raramente referida em estudos de pacientes com problemas respiratórios associados ao sono (SRRD). A observação ocasional de espetacular aumento da $f$ durante o sono em pacientes com SRRD, principalmente apnéias/hipopnéias associadas à desaturação da oxi-hemoglobina, nos levou a proceder a estudo retrospectivo de 650 exames consecutivos de polissonografia (PSG), com a finalidade de avaliar a frequência da ocorrência desta aceleração da $\mathbf{f}$ e dos prováveis fatores a ela associados. Foram excluidos deste estudo pacientes com insuficiência respiratória grave. Observamos a ocorrência deste fenômeno em 16 pacientes (11 homens com média de idade $45 \pm 13$ anos, índice de massa corporal (BMI) $44 \pm 11 \mathrm{~kg} / \mathrm{m} 2$ ) para os quais a foi maior que 25 min-1 durante o sono (grupo de taquipnéicos, T). Realizamos comparação da f entre $\mathrm{I}$ e grupo controle (C) de pacientes de mesmo sexo e semelhantes

*Sleep Laboratory, St. Luc Training Hospital Université Catholique de Louvain, Brussels. Aceite: 11-setembro-1992.

Dra. Márcia Pradella - Laboratoire de Sommeil, Hopital St. Luc - Avenue Hippocrate 10 1200 Brussels - Belgium. 
idades (45 \pm 12 anos) e, $B M I\left(44 \pm 10 \mathrm{~kg} / \mathrm{m}^{2}\right)$ e SRRD, tm cada estado de vigilância, fazendu média de 5 contagens da $f$, cada uma feita durante 1 minuto e durante um periodo estável do determinado estado de vigilância. Observamos que: os pacientes do grupo $\mathbf{C}$ não apresentaram alteração significativa da f em qualquer estado de vigilância; os pacientes do grupo $T$ já tinham $\mathbf{f}$ maior que os pacientes do grupo $\mathrm{C}(\mathrm{p}<0.05$ ) quando acordados e esta aumentou significativamente em todos os estados do sono $(p<0.01 \mathrm{f}$ quando acordados vs 1 durante o sono, $p<0.001 \mathrm{~T}$ vs $\mathrm{C}$ durante o sono). Comparamos os dois grupos para vários parâmetros clínicos e polissonográficos. Diferença estatisticamente significante foi observada nara os dados de: PaCO2 (pressão arterial do CO2), capacidade vital (VC), volume expiratório em 1 segundo (FEV1) e da frequência do pulso (PF) durante repouso (acordados) e durante o sono.

PALAVRAS-CHAVE: frequência respiratória, registro polissonográfico, problemas respiratórios relacionados ao sono.

\section{RESPIRATORY PHYSIOLOGY DURING WAKEFULNESS AND SLEEP}

1. Sleep organization. Wakefulness on the one hand is a state of cortical activation recognized by the occurence of alpha waves (during quiet periods) on the electroencephalogram (EEG) and increased muscle tone. The cortical activation is maintained by tonic activity of the reticular activating system, which both directly stimulates the cortex and also facilitates thalamic relay neuron passage of sensory information to the cortex. Sleep on the other hand is a state in which alpha activity is lost and muscle tone reduced. NREM sleep (stage 1-4) is characterized by inhibition of the reticular activating system, resulting in cortical suppression and functional deafferentation. In REM sleep, the reticular activating system is reactived, producing cortical stimulation. In contrast to wakefulness both sensory and motor functions are impaired during REM. There is both pre- and post-synaptic inhibition of afferent neurons resulting in raised arousal thresholds to external stimuli and post-synaptic inhibition of motor neurons which produces the postural atonia typical of REM sleep 11.

2. Ventilation. Feedback regulation through chemoreceptors is one of the two major mechanisms controlling ventilation. It adjusts ventilation to changes in the environment and metabolic rate. The other one is under volitional control, and can override, under certain limits, the metabolic one. This usually happens when the respiratory system is disturbed so as to change the partial pressure of $\mathrm{O} 2$ or $\mathrm{CO} 2$ in the blood, smooth adjustments in ventilation are expected 28. The special attributes of the brain-stem respiratory neurons may not be inherent automaticity, but rather a consequence of their afferent inputs and their ability to convert these inputs into a rhythmic output. Thus, breathing rhythm would not be simply modulated by afferent respiratory stimuli but rather would be critically and fundamentally dependent on such stimuli 33 . The activation of each inspiratory burst (on-switch mechanism) is the critical event in the generation of the respiratory patterns and depends on adequate levels of afferent respiratory stimuli. The major influence of incoming afferent stimuli is to determine the timing of the onset of each respiration and, in so doing, to fix the duration of the preceding expiration, thereby generating the basic respiratory rhythm 33,39 . Under normal conditions, effective respiratory rhythmicity is critically linked to, and dependent on the need for removal of $\mathrm{CO} 2$; other respiratory stimuli exert a more secondary modulating influence, but do not in themselves generate the respiratory rhythm.

\section{The effect of sleep stages on ventilation.}

3.1. Breathing patterns: (1) Drowsiness or unsteady NREM sleep is characterized in many subjects by periodic breathing associated with swings in $\mathrm{PO} 2$ and PCO2, cortical EEG activity, systemic arterial pressure (AP), heart rate, $\mathrm{O} 2$ saturation $(\mathrm{SaO} 2)$ and an overall moderate decrease in ventilation 29 . (2) The irre- 
gularity of breathing at sleep onset consists of a regular waxing and waning of breathing amplitude. The oscillations may be of low amplitude resulting in alternating hyper- and hypoventilation or of large amplitude with apneas at the nadir of the oscillations. During the amplitude oscillations there are few changes, if any, in respiratory rate 12,45. Apneas occur more frequently in the elderly and not only at the transition between wakefulness and sleep, but also tend to occur predominantely in sleep stages 1-2. They seem to be an exaggeration of the periodicity that is typical of sleep onset $6,37,44$. (3) Periodic breathing persists as long as sleep oscillates between arousal and stages 1 or 2. These oscillations seem to be mainly due to sleep instability at these stages and different setpoints of breathing regulation in wakefulness and sleep; the natural tendency of breathing regulation to be unstable probably aggravates this situation. It disappears when stable stage 2 or stages 3-4 are reached and systemic AP drops $20-30 \%$ below basal wakefulness values 13,43 . (4) FEM sleep is characterized by erratic shallow breathing with irregularities both in amplitude and frequency. The heart rate becomes irregular and central apneas or hypopneas occur sporadically. Hipertensive peaks, sometimes reaching $30-40 \mathrm{mmHg}$, suddenly appear and continue for the whole length of REM sleep. These events are synckroncus with REM bursts and probably of central origin, related to the REM sleep process.

3.2. Ventilation. In normal healthy adults the minute ventilation (VE) decreases by a mean of $8.2 \pm 2.3 \%$ from wakefulness to sleep and aoes not vary sig. nificantly between sleep stages $18,38,45$. The greatest decrease in ventilation has been observed during phasic REM sleep 11,14. Mean inspiratory flow fell significantly but timing was unchanged 33,38 . Arterial oxygen saturation (SaO2) also fell and could be accounted for entirely by the associated reduction in ventila. tion. $\mathrm{O} 2$ (VO2) consumption and $\mathrm{CO} 2$ (VCO2) production also fell by $8.5 \pm 1.6 \%$ and $12.3 \pm 1.7 \%$ respectively during sleep and again did not differ between sleep stages. Ventilation correlated quite closely with $\mathrm{VO} 2$ and VCO2 during sleep with similar levels of correlation found for each sleep stage. These results are similar to those observed in younger 14,21 or older subjects 37,41 .

3.3. Breathing frequency (f). Breathing frequency (f) varies significantly from one individual to an other but a remarkable stability is observed for the same subject $1,14,31,35-38,42$. For healthy awake subjects the mean is 8 to 24.8 breaths/ $\mathrm{min}$ for the young and 8.14 to $18.06 \mathrm{breaths} / \mathrm{min}$ for the elderly $(>65$ years $)$. In sleep $\mathrm{f}$ ranges from 9.9 to $23.6 \mathrm{breaths} / \mathrm{min}$ for the young and 5.16 to 19.64 brea. ths/min for the elderly. The lower respiratory frequency observed in the elderly was primarily due to a significantly longer inspiratory time compared with values observed in wakefulness and each sleep stages in the young ${ }^{37}$. In children, Guilleminault 16 describes the association of tachypnea with the rare occurrence or absence of apnea during sleep with or without a decrease of oxygen saturation which could be proposed as a marker of pathological breathing during sleep. Aubert-Tulkens et al 2 reported a case of a woman with obesity, loud snoring, restless sleep, hypersomnia, personality changes and systemic hypertension, who on polysomnographic examination revealed tachypnea of 35 breaths/min, continuous loud snoring and an $\mathrm{SaO} 2$ with periodic oscillations between $95-60 \%$.

3.4. Upper airway. Breathing implies maintenance of a normal upper airway patency: many local reflexes at the naso-oro-hypopharyngeal and laryngeal level are thought to counteract the progressive development of the negative intrathoracic pressure generated by the inspiratory muscles (scaleni, intercostals, diaphragm) contraction. The reflexes involved in the maintenance of upper airway patency are, of course, activated just prior to the onset of the diaphragmatic contraction.

The passage from wakefulness to sleep is normally associated with an increased upper airway muscle tone. Whether the increase in upper airway resistance alone explains the decrease in ventilation during sleep is not yet clear 1,17,20,25,40,41.

4. Sex differences - Caterall and co-workers 5 reported that there was no sex difference in sleep disorders in subjects with normal body weight. In female subjects, disordered breathing was reduced during pregnancy 4 and increased after menopause 3 . Progesterone is known to be a respiratory stimu- 
lant 11,22,46. Obese women (but not obese men) show an increased response to both hypoxia and hypercapnia 27.

5. Diseased subjects. Tobin et al.42 studied $f$ in awake normal and diseased subjects and observed that respiratory rate was increased above the normal in smokers and in patients with COPD, restrictive lung disease and pulmonary hypertension but remained normal in asthmatic patients (11 to 22.2 breaths $/ \mathrm{min}$ in normals, 12.1 to 43.7 breaths/min in diseased subjects).

PROPOSAL. The present study's main aim is to determine the frequency with which tachypnea occurs during sleep in patients referred to our laboratory (Sleep Laboratory, St Luc Training Hospital, Brussels, Belgium) for clinical assessment of sleep apnea syndrome. We were impressed by the fact that contrary to what is normally described in current literature on the subject, instead of reducing $f$ during sieep, several subjects showed a spectacular increase in $f$. With this in mind, we undertook a retrospective study of 650 all night polysom: nographic recordings (excluding patients with major respiratory failures) and found 16 patients who presented a significant increase of $f$ during sleep $(p<0.01)$. We set up a control group $(n=16)$ of patients with similar sleep disturbances but normal $f$ during sleep, matched for sex, age and body mass index in an attempt to establish any distinguishing factors between them.

\section{METHODS}

Population. In a study of 650 consecutive all-night polysomnographic recordings, we found 16 patients who had $f$ higher than 25 min-1 during sleep ( $T$ group). The main diagnosis of SRRD comprised 9 patients with sleep apnea-hypopnea syndrome, 3 with an overlap syndrome, 1 with a hypoventilation syndrome, 1 with Shy-Drager syndrome associated with snoring, 1 with chronic obstructive pulmonary disease (COPD) and 1 with major obesity associated with $\mathrm{SaO} 2$ desaturations essentialy in REM sleep. We constituted a control group of patients $(\mathrm{n}=16)$ with similar SRRD (i.e. apnea-hypopnea, snoring, SaO2 desaturations) but normal $f$ during sleep, matched with $T$ for sex, age and BMI (C group) and a group of young healthy subjects (15 males; age: $24 \pm 2$; BMII $21 \pm 2$ (N group) for comparison with the $\mathbf{T}$ group.

Polysomnographic studies. The polysomnographic recordings were performed according to standard techniques 34: electroencephalogram (EEG), electroocuiogram (EOG), electromyogram (EMG), electrocardiogram (ECG), oral and nasal airflow (thermocouples placed in front of mouth and nostrils), respiratory movements (strain gauge), breathing sounds, i.e., snoring (microphone attached to the skin over the larynx). These parameters were recorded on a polygraph at a paper speed of 15 or $10 \mathrm{~mm} / \mathrm{s}$.

Since 1986, transcutaneous oxygen saturation (SaO2) (Nellcor pulse oxyleter N-100, Hayward, CA, USA) has also been recorded. The mean of ten measurements per second of SaO2 and pulse frequency (PF) from the oximeter, along with the integrated signal from the microphone were stored in an intermediate data bank every 6 seconds. The file containing these measurements also held information on the exact time of the start of recording. This allowed us to correlate these data at a later stage along with other data, namely data of the vigilance stages and apneas. The desaturation index (DI) was taken as the number of the desaturations episodes $\geqslant 4 \%$ expressed per hour of sleep.

Sleep staging was performed according to standard methods in 40 or 60 seconds epochs. Total sleep time (TST) was measured from the moment when the patient fell asleep until the final awakening. excluding wake time during sleep. The time of the various sleep stages was calculated as percentage of TST. Movement arousal index (MA) is the number of episodes of increase in EMG accompanied by alpha rhythm in the EEG for at least 2 seconds, during a sleep epoch, expressed per hour of sleep.

Study. We compared $f$ (from airflow) in each vigilance state by averaging five measurements of $f$, each of one minute duration in a stable period for: (a) the $T$ group (wakefulness vs stages 1, 2, 3, 4 and REM sleep); (b) the C group (idem to T group); (c) the $\mathbf{N}$ group (idem to $\mathbf{T}$ group) and $\mathbf{T}$ vs $\mathbf{C}$ group (in each vigilance state). We compared the $\mathbf{T}$ and $\mathrm{C}$ groups for other polysomnographic variables: \% stage 1, 2, 3, 4 and REM sleep; MA; $\mathrm{SaO} 2$; DI and PF and for some clinical variables: blood pressure (BP); blood gas (PaO2 and PaCO2); vital capacity (VC) and forced expiratory volume at one second (FEV1).

Statistical analyses. The $t$-paired test was used for analyses within groups. The t-test for two means was used for the comparisons between T vs C groups. 


\section{RESULTS}

Analysis of the results highlighted the following elements:

1. by definition, $T$ and $C$ groups were well matched for age and $\mathrm{BMI}(\mathrm{mean} \pm \mathrm{SD}$; age: $45 \pm 13$ yrs vs $45 \pm 12$ yrs; BMI: $44 \pm 11 \mathrm{~kg} / \mathrm{m} 2$ vs $44 \pm 10 \mathrm{~kg} / \mathrm{m} 2$ );

2. $T$ patients showed a higher $f$ during wakefulness than $C$ patients $(23.4 \pm 6.5 \mathrm{~min}-1 \mathrm{vs}$ $17.9 \pm 3.0 \mathrm{~min}-1 ; \mathrm{p}<0.05)$;

3. C patients showed no significant modification of $f$ in any sleep stage:

4. $\mathrm{T}$ patients increased $\mathrm{f}$ in all sleep stages (stage $1: 31.5 \pm 7.7$ min-1; stage $2 ; 31.9 \pm 7.2 \mathrm{~min}-1$; stage 3: $31.0 \pm 6.0$ min-1; stage 4 : $30.3 \pm 6.5$ min-1; stage REM: $29.3 \pm 4.0 \mathrm{nin}-1$; all $11<0.01$ vs wakefulness) ;

5. $\mathrm{N}$ subjects showed no significant modification of $f$ in any vigilance stage;

6. T and $C$ patients showed no significant difference for the distribution or the sletes stages;

7. $\mathbf{N}$ subjects showed a normal distribution of sleep stages: stage 1: 10.0土4.7; stage 2: 48.5 \pm 9.1 ; stage $3: 7.7 \pm 4.2$; stage $4 ; 15.2 \pm 6.8$; stage REM: $18.6 \pm 6.4 \%$ TST$^{\prime}$;

8 . 'T and $\mathrm{C}$ patients showed no significant difference for: MA, SaO2, DI, BP and PaO2;

9. $\mathrm{N}$ subjects showed a mean SaO2 during TST of $97.2 \pm 1.0 \%$ and a number of MA/hs of $12.0 \pm 6.1$

10. a significant statistical level of difference was observed between $T$ vs $C$ group for: PaCO2 $(44.2 \pm 6.0$ vs $39.1 \pm 3.1 \mathrm{mmHg} \mathrm{p}<0.05)$; $\mathrm{VC} \quad(76.2 \pm 11.3$ vs $83.2 \pm 7.8$ percent predicted normal $\mathrm{p}<0.05)$; FEV1 (77.0 \pm 12.9 vs $86.3 \pm 10.0$ percent predicted normal $p<0.05) ; P F$ (awake: $84.2 \pm 13.3$ vs $74.3 \pm 8.9 \mathrm{~min}-1$; TST: $80.0 \pm 13.6$ vs $69.8<9.6$ min-1 $\mathrm{p}<0.05$ for wakefulness and sleep) and $f$ in all vigilance states (wakefulness $p<0.05$; stage $1,2,3$ and 4 sleep $p<0.001$; REM sleep $p<0.05$ ) (see Fig. 1 and Table 1).

E

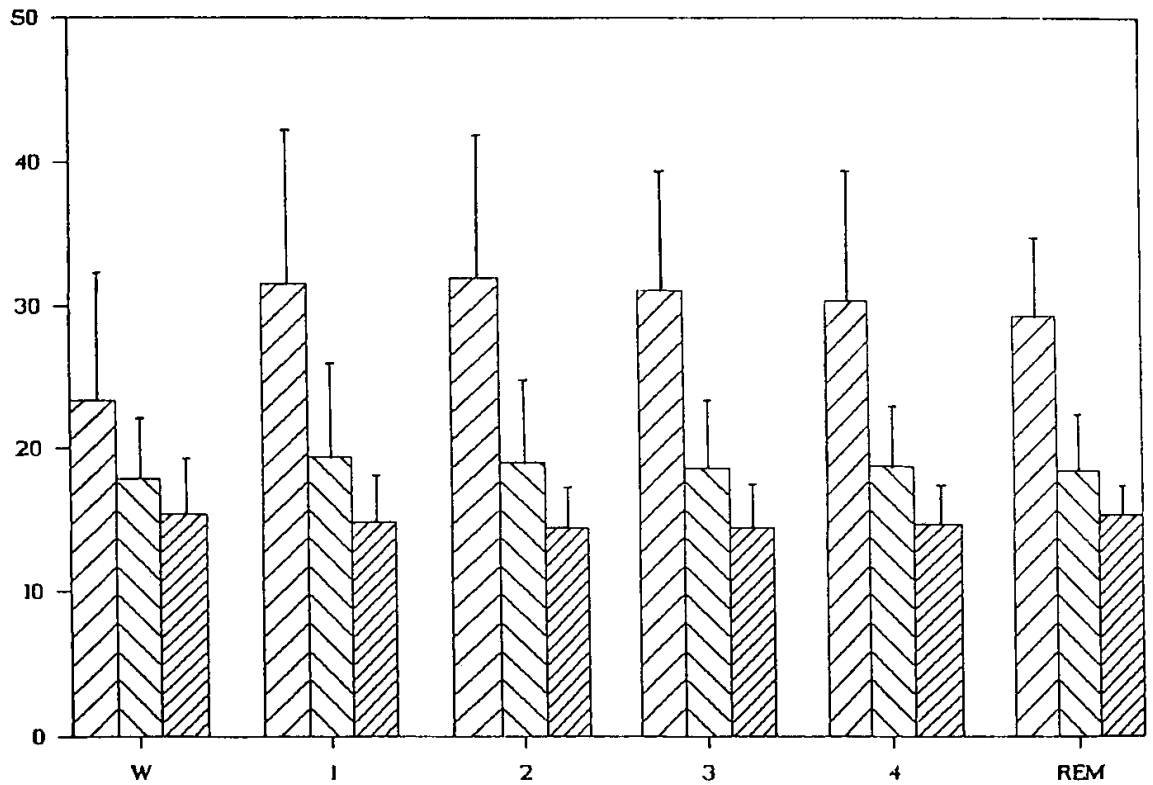

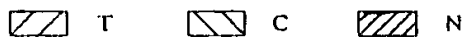

Fig. 1. Breathing frequency. 
Table: 1. Statistical significative level of comparison between the two paticnts population ( $T$ vs C) for: breathing frequency (f), PSG and clinical variables (see text).

Statistical analyses ( $T$ vs $C$ )

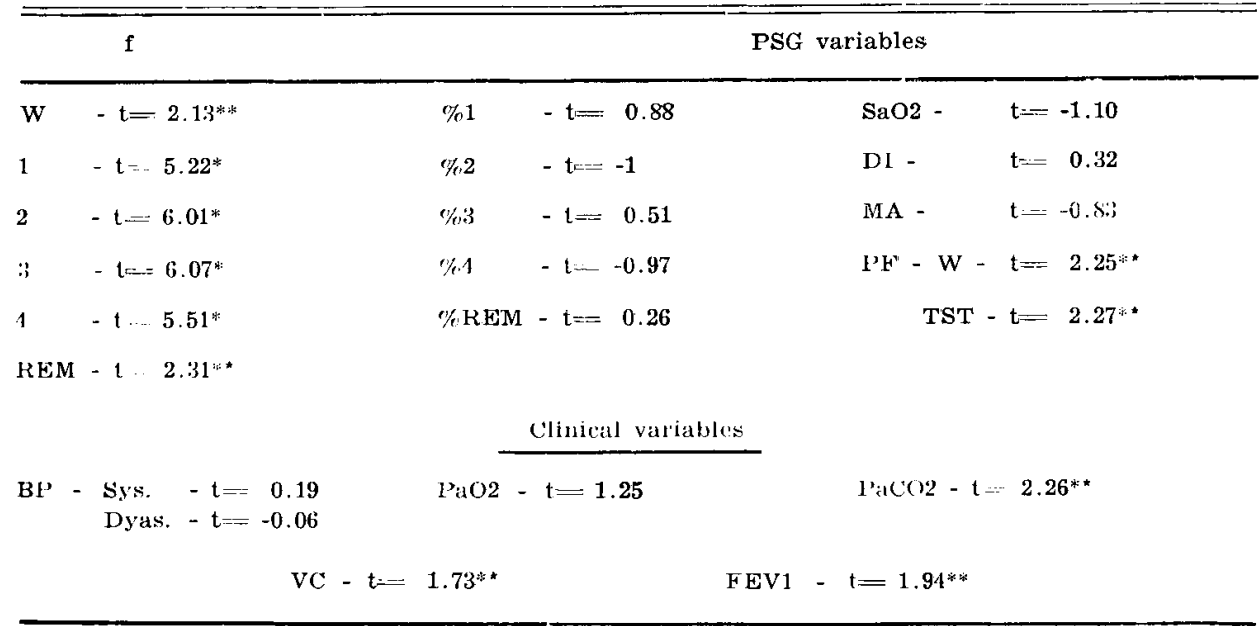

Student't: $p<0.001^{*} ; \mathrm{p}<0.05^{* *}$

\section{COMMENTS}

Discussion. An acceleration of $f$ during sleep is rarely confirmed in a review of current literature. In females and children, tachypnea may be considered a marker of pathologic breathing during sleep; which could be associated with loud snoring, and oxygen desaturation with or without the occurence of apneas or hypopneas 2.16 . In this study, we found 16 patients from a population of 650 subjects $(2.5 \%)$ who presented a significant acceleration of $\mathrm{f}$ during sleep. All but two of these patients (one female, BMI of $19.78 \mathrm{~kg} / \mathrm{m}^{2}$, who suffered from Shy-Drager syndrome and one male, BMI of $27.68 \mathrm{~kg} / \mathrm{m}^{2}$, who suffered irom DPOC) suffered from morbid obesity and were referred to us for investigation of sleep apnea syndrome.

In relation to the main diagnosis of SRRD presented by our patients: The alveolar hypo-ventilation syndrome is defined as a combination of hypercapnia and alveolar hypoxemia. Nonspecific alveolar hypoventilation can occur secondary to damaged respiratory centers in the brain and can also be seen with drug intoxication (barbiturates, for example) and with abnormalities of breathing apparatus, as in muscular dystrophy, kyphoscoliosis, Pierre Robin syndrome, obstructice lung disease, etc. The Pickwickian syndrome, in its classic form includes obesity, hypersomnolence, periodic breathing with hypoventilation and cor pulmonale 15. In obesity, the total lung volume and the functional residual capacity are diminished. The decrease in functional residual capacity is secondary to a marked diminution in expiratory volume. Because of the diminished volu. mes, the obese patient breaths closer to residual volume. This, coupled with a decreased tidal volume allows for earlier airway closure in areas of decreased ventilation 46. Sleep studies indicate that the incidence of obstructive sleep-apnea (OSA), obesity-hypoventilation syndrome and desaturation in unselected, morbidly obese male patients is extremely high 19 . Obese children and adolescents are undoubtedly at risk as a group for OSA in adulthood 30 . Kunitomo et al 27 showed that there is no sex-related difference in ventilatory or occlusion pressure responses to hypoxia or hypercapnia in either obese subjects or normal control subjects. However, there is respiratory compensation with mass loading i.e. accumulation of fat about the chest wall that produce a decrease in chest wall and lung compliance 46 in obese women but not in obese men 9,27 . In obese women, an increased severity of oxygen desaturation and the appearance of sleep 
apnea is often seen after the menopause. Progesterone has been considered as a protective hormone in females 45 . Among our tachypneic group, 4 women presented a morbid obesity and 2 were in a post-menopausal age. Harman et al 19 suggest that for obese men anatomic factors would appear to be important. Increased fatty tissue in the hypopharynx may predispose to obstructive apnea. Kopelman et al 23 believe that mechanical impedance of breathing due to abdominal adipose tissue combined with abnormal central respiratory control i.e. relatively depressed chemosensitivities 27 are the major factors responsible for the respiratory disturbances observed during sleep. All of our obese patients presented obstructive sleep apnea-hypopnea, periodic breathing or snoring associated with $\mathrm{SaO} 2$ desaturation.

In patients with Shy-Drager syndrome, there is evidence of multiple system atrophy due to widespread degeneration throughout the central nervous system. Respiratory abnormalities in these patients may be due to laryngeal obstruction caused by bilateral abductor paralysis of the vocal cords, or to disorganization of central respiratory control, i.e., functional instabilities inherent in the organization of respiratory rate and rhythm ${ }^{8}$. These may produce episodes of sieep apnea with concomitant hypoxia which mav presage death due to cardiorespiratory arrest 21 . Our patient had a tachypnea associated with snoring observed in $100 \%$ of the TST. These are compatible with the patophysiologic findings described above.

In chronic obstructive pulmonary disease (COPD), Tobin et al 42 observed an elevated respiratory rate during wakefulness, similar in patients with or without hypercapnia, when compared with normal subjects and symptomatic asthmatic patients. They postulated that, since the severity of resistive loading as reflected by the airway resistance was comparable among the two COPD groups and symptomatic asthmatic patients, the faster respiratory rate in patients with COPD implied a proportionally greater fall in compliance which shortened the time constant of the respiratory system. Compliance of the respiratory system was equivalent to the sum of the reciprocals of the lung and thoracic wall compliances. Dynamic lung compliance probably decreased to approximately the same extent in COPD as in symptomatic asthma and would not account for the more rapid rate in COPD. The chronically hyperinflated thorax in COPD appeared to be less compliant than normal. In their patients, the most specific variability in the components of the breathing pattern appeared to be expiratory timing. This concurs with the hypothesis of Sullivan et al 39 that the mechanism initiating inspiratory burst, rather than the one responsible for terminating the burst, is of fundamental importance in setting up breathing frequency.

A commentary may be made in relation to smokers. Tobin et al 42 observed an increased respiratory rate with heightened respiratory center drive as reflected by elevated mean inspiratory flow (VT/TI) in smokers who had little or no subjective complains. In our series of patients, 6 tachypneic patients and 4 control patients were smokers. This enabled us to exclude the effect of a higher respi. ratory center set point induced by chronic intermittent stimulation with nicotine with a factor allowing us to differentiate $\mathbf{T}$ and $\mathbf{C}$ patients.

Conclusion. Our results confirm the data observed in literature for normal subjects in relation to the stability of $f$ within a subject, independent of vigilance states and the inter-individual variability that exists $35,37,38$. We believe that for the majority of our tachypneic patients, the most likely hypothesis that may explain the observed acceleration of breathing frequency during sleep is that this was due to the morbid obesity associated with the diminution of pulmonary volumes (VC and FEV1) and hypercapnia. The reduction in pulmonary volumes may potencialise ventilatory decreases normally observed during sleep, enhancing the development or underscoring and increasing the hypercapnia that already exists. This in turn induces tachypnea and tachycardia (detected as PF) as a compensatory mechanism.

\footnotetext{
Acknowledgements - The author would like to thank director of the Sleep Laboratory at St. Luc training Hospital Prof. G Aubert and the Consultant Pneumologist of the same laboratory Prof. D. Rodenstein for their helpful remarks in the writing up of this study.
} 


\section{REFERENCES}

1. Askanazi J, Silverberg P, Foster R, Hyman A, Milic-Emili J, Kinney J. Effects of respiratory apparatus on breathing pattern. J Appl Physiol 1980, 48:577-580.

2. Aubert-Tulkens G, Rodenstein DO, Culée C, Stanescu DC. Sleep apnea syndrome without apnea. In Chouard CH (ed): Chronic rhonchopathy. John Libbey Eurotext, 1988 p 152-156.

3. Block AJ, Wynne JW, Boysen PG. Sleep-disordered breathing and nocturnaI oxygen desaturation in post-menopausal women. Am J Med 1980, 69:75-79.

4. Brownell LG, West $P$, Kriger MH. Breathing during sleep in normal pregnant women. An Rev Respir Dis 1986, 133:38-41.

5. Catterall JR, Calverley PMA, Shapiro CM, Flenley DC, Douglas NJ. Breathing and oxygenation during sleep are similar in normal men and normal women. Am Rev Respir Dis 1985, $132: 86-88$.

6. Cherniack NS, von Euler C, Glogowska M, Homma 1. Characteristics and rate of occurrence of spont and provoked augmented breaths. Acta Physiol Scand 1981, 111:349-360.

7. Cherniack NS. Respiratory dysrhythmias during sleep. N Engl J Med 1981, 305:325-330.

8. Chester C, Gottfried S, Cameron D, Strohl K. Pathophysiologic findings in a natient with Shy-Drager and alveolar hypoventilation syndromes, Chest 1988, 94:212-214.

9. Derderian S, Rajagopal K. Obesity, gender and sleep. Chest 1988, 93:900-901.

10. Douglas NJ, White DP, Picket CK, Weil JV, Zwillich CW. Respiration during sleep in normal man. Thorax 1982, 37:840-844.

11. Douglas NJ. Control of breathing during sleep. Clin Sci 1984, 67:465-472.

12. Duron B, Andrag C, Laval P. Ventilation pulmonaire globale CO2 alvéolaire et cunsonnmation d'oxigène au cours du sommeil normal C R Soc Biol 1968, 162:139-145.

13. Duron B. La fonction respiratoire pendant le sommeil physiologique. Bull Cur Physiopath Resp 1972, 8:1031-1057.

14. Gould GA, Gugger M, Molloy J, et al. Breathing pattern and eye movement density during REM sleep in humans, Am Rev Respir Dis 1988, 138:874-877.

15. Guilleminault C, Tilkian A, Dement W. The sleep apnea syndromes. Annu Rev Med 1976, 27:465-484.

16. Guilleminault C. Obstructive Sleep Apnea Syndrome and its treatment in children: areas of agreement and controversy. Ped Pulm 1987, 3:429-436.

17. Guilleminault $C$. The role of sleep and sleep states on breathing disorders. Schw Med Wschr 1988, 118:1331-1332.

18. Haddad GG, Epstein RA, Epstein MA, Leistner HL, Marino PA, Mellins RB. Maturation of ventilation and ventilatory pattern in normal sleeping infants. $J$ Appl Physiol 1979. 46:998-1002.

19. Harman E, Wynne JW, Block AJ, Malloy-Fisher L. Sleep-disordered breathing and uxygen desaturation in obese patients. Chest 1981, 79:256-260.

20. Hudgel DW. Martin RJ, Johnson B. Mechanics of the respiratory system and breathing pattern during sleep in normal hurnans. J Appl Physiol 1984, 56:133-137.

21. Kenyon (FS, Apps MCP, Traub M. Stridor and obstructive sleep apnea in Shy-Drager syndrome treated by laryngofissure and cord lateralization. Laryngoscope 1984, 94:11061102.

22. Kimura H, Tatsumi K, Kuriyama T, Sugita T, Watanabe S, Nishibayashi Y. Effect of chlormadinone acetate a synthetic progesterone on restoring impaired load compensation in chronic obstructive pulmonary disease. Tohoku $J$ Exp Med 1986, 149:119-132.

23. Kopelman PG, Apps MCP, Cope T, Ingram DA, Empey DW, Evans SJ. Nocturnal hypoxia and sleep apnoea in asymptomatic obese men. Int $J$ Obes 1986, 10:211-217.

24. Krieger J, Turlot JC, Mangin P, Kurtz D. Breathing during sleep in normal young and elderly subjects: hypopneas, apenas and correlated factors. Sleep 1983, 6:108-120.

25. Krieger J. Breathing during sleep in normal subject. Clin Chest Med 1985, 6:577-594.

26. Krieger J, Maglasiu N, Sforza $\mathbf{E}$, Kurtz D. Breathing during sleep in normal middleage subject. Sleep 1990, 13:143-154.

27. Kunitomo F, Kimura H, Tatsumi K, Kuriyama $\mathbf{T}$, Watanabe $\mathbf{S}$, Honda $\mathbf{Y}$. Sex differences in awake ventilatory drive and abnormal breathing during sleep in eucapnic obesity. Chest 1988, 93:968-976.

28. Longobardo G, Cherniack N, Gothe B. Factors affecting respiratory system stability. Ann Bioeng 1989, 17:377-396.

29. Lugaresi E, Cirignotta F, Mondini S, Montagna P, Zucconi M. Sleep-related respiratory disorders. Ital J Neurol Sci 1985, 6:389-399.

30. Mallory G, Fiser D, Jackson R. Sleep-associated breathing disorders in morbidly obese children and adolescents. J Pediatr 1989, 115:829-897. 
31. Naifeh $\mathbf{K H}$, Kamiya $J$. The nature of respiratory changes associated with sleep onset. Sleep 1981, 4:49-59.

32. Phillipson EA. Control of breathing during sleep. Am Rev Respir Dis 1978. 118:909-939.

33. Phillipson E, Duffin J, Cooper J. Critical dependence of respiratory rhythmicity on metabolic CO2 load. J Appl Physiol 1981, 50:45-54.

34. Rechtschaffen A, Kales A. A manual of standardized terminology, techniques and scoring system for sleep stages of human subjects, Los Angeles: UCLA, 1968.

35. Shea SA, Walter J, Murphy $K$, Guz A. Evidence for individuality of breathing patterns in resting healthy man. Resp Physiol 1987, 68:331-344.

36. Shea SA, Horner RL, Banner NR, Mckenzie E, Heaton R, Yacoub MH, Guz A. The effect of human heart-lung transplantation upon breathing at rest and during sleep. Respir Physiol 1988, 72:131-149.

37. Shore ET, Millman RP, Silage DA, Chung DCC, Pack AI. Ventilatory and arousal patterns during sleep in normal young and elderly subject. J Appl Physiol 1985, 59:1607-1615.

38. Stradling JR, Chadwick GA, Frew AJ. Changes in ventilation and its components in normal subjects during sleep. Thorax 1985, 40:364-370.

39. Sullivan C, Kozar L, Murphy E, Phillipson E. Primary role of respiratory afferents in sustaining breathing rhythm. J Appl Physiol 1978, 45:11-17.

40. Sullivan CE, Issa FG. Pathophysiological mechanisms in obstructive sleep apnea. Slefl 1980, 3:235-2A6.

41. Tabachnik E, Muller NL, Bryan AC, Levison $H$. Changes in ventilation and chest wall mechanics during sleep in normal adolescents. J Appl Physiol 1981, 51:557-564.

42. Tobin M, Chadha $T$, Jenouri G, Birch S, Gazeroglu H, Sackner M. Breathing patterns: diseased subjects.. Chest 1983, 84:286-294.

43. Vibert JF, Foutz AS, Cailie D, Hugelin A. Respiratory rhythm multistability during sleep-wake states. Brain Res 1988, 448:403-405.

44. Webb P. Periodic breathing during sleep. J Appl Psysiol 1974, 37:899-903.

45. White DP, Weil JV, Zwillich CW. Metabolic rate and breathing during sleep. J Appl Physiol 1985, 59:384-391.

46. Wittels E. Obesity and hormonal factors in sleep and sleep apnea. Med Clin North Am 1985. $69: 1265-1280$. 